\title{
A Erosão das Bases do Estado Social de Direito e o Impacto na Efetivação dos Direitos Sociais
}

\author{
Erosion of the Basis of the Social State \\ OF LAW AND THE IMPACT ON THE EFFECTIVENESS \\ of Social Rights
}

\author{
Osvaldo Ferreira de Carvalho *
}

Resumo: O presente estudo versa sobre a erosão das bases do Estado Social de Direito e o impacto na efetivação dos direitos sociais. Procede-se a uma análise desde as origens do constitucionalismo moderno até o advento do constitucionalismo social, o qual é responsável pela instituição do Estado Social. São realçados os objetivos do Estado Social de Direito ao se traduzir em programas constitucionais que se expressam na solidariedade social e na consecução da justiça social. Ressalta-se a crise do modelo de Estado Social refletida no campo dos direitos sociais que se debilitam em razão da dependência de recursos que são escassos e de fatores alheios no âmbito de determinação do próprio Estado. Firma-se posição ao encetar o argumento de que a exigência da efetivação, da realização dos direitos sociais se assenta na dignidade da pessoa humana ao compelir ações estatais necessárias para a concretização destes direitos.

Palavras-chaves: Constitucionalismo social. Estado Social. Crise. Efetivação dos direitos sociais. Dignidade da pessoa humana.

Abstract: The present study deals with the erosion of the foundations of the Social State of Right and the impact on the fulfillment of social rights. Proceeds to an analysis from the origins of modern constitutionalism until the advent of social constitutionalism, which is responsible for instituting the Social State. Are highlighted the objectives of the Social State of Right to translate into programs that are expressed in constitutional social solidarity and the pursuit of social justice. It is highlighted the crisis of the Social State reflected in the field of social rights that weaken because of the dependence of resources that are

* Doutorando em Direito pela Universidade de Lisboa. Mestre em Direito. Professor universitário nos cursos de Graduação e Pós-Graduação. Pesquisador da Fundação de Amparo à Pesquisa no Estado de Goiás. E-mail: osvaldopesquisador@gmail.com scarce and factors beyond the scope of determining the state itself. Firm up position to launch the argument that the requirement of performance, the realization of social rights is based on human dignity to compel state action necessary to achievement these rights.

Keywords: Social constitutionalism. Social State. Crisis. Fulfillment of social rights. Human dignity. 


\section{INTRODUÇÃO}

O estudo que ora se submete ao debate e à crítica versa sobre a erosão das bases do Estado Social de Direito e o impacto na efetivação dos direitos sociais. Perquirir-se-á se é plausível a exequibilidade ou concretização dos direitos sociais na ambitude do atual Estado Social de Direito sob um contexto de insustentabilidade econômico-financeira. $\mathrm{O}$ objeto escolhido predispõe-se a discussões políticas, econômicas e filosóficas ao projetar questões como as seguintes: quais são as tarefas do Estado Social perante os indivíduos? É possível manter determinados níveis de prestação estatal ante as novas demandas e de condições econômicas adversas? Afinal, quais são os objetivos do Estado Social? Estão estes objetivos jungidos a uma permanente evolução positiva? É admissível conciliar escassez de recursos com a imposição de efetivar direitos sociais reconhecidos constitucionalmente?

A atualidade do tema é evidente em razão da fragilização que vêm submetendo os direitos sociais em um cenário de ondas neoliberais de reforma do Estado, de redimensionamento do aparato estatal ante a crise do modelo intervencionista do Estado Social. Simplificadamente, a crise deste modelo de Estado tem sido associada ao agigantamento do aparelho estatal, à exaustão dos modelos de financiamento do Estado e à ineficiência dos métodos de gestão estatal. Nesse quadro, os direitos sociais permanecem em posição frágil nos ordenamentos jurídicos estatais. Além disso, debilitam-se tais direitos na dependência de recursos que se apresentam escassos e de fatores que nem sempre estão no âmbito de determinação do Estado.

Os objetivos dos direitos sociais parecem encontrar uma série de dificuldades para a sua realização: a distribuição de recursos e o atendimento das necessidades materiais básicas parecem não ser obtidos, cujo rol sempre é suscetível de alargamento. Embora não se possa negar os processos de reforma conduzidos no horizonte desta chamada crise do Estado Social, igualmente não se deva rechaçar que a evolução experimentada em matéria dos direitos fundamentais, com a explícita positivação (ou constitucionalização) dos direitos sociais ocorridos com o impulso do constitucionalismo social, não devem ser simplesmente ignorados e suprimidos no quadro de institucionalização do Estado Social de Direito ao ter como vértice a dignidade da pessoa humana.

Feito esse enquadramento, o presente ensaio teve origem na investigação no curso de aprofundamento conducente ao Doutoramento em Ciências JurídicoPolíticas na Faculdade de Direito da Universidade de Lisboa, no âmbito da 
disciplina regida pelo Professor Doutor António Pedro Barbas Homem, no ano letivo 2011/2012; compreendem-se certas de suas peculiaridades, mormente sua dimensão, o tratamento sintético de certos aspectos, porém são compensadas com amplas incursões na doutrina portuguesa, bem como na brasileira, e pelo recurso a outras obras de referência.

Neste contexto, elucida-se a opção pela delimitação desta análise teórica ao principiar sobre a evolução do constitucionalismo que se dá concomitantemente com a sua expressão na estruturação do Estado de Direito que tem por fundamento comum a ampliação e busca de efetividade para os direitos fundamentais; circunscreve-se, pois, a investigar os motivos justificadores do processo de erosão das bases do Estado Social e o impacto frontal na realização, na efetivação dos direitos sociais.

Demarcado o problema e o objeto deste ensaio em sucintas linhas e alinhavadas as observações preliminares, explicita-se a estruturação de seu desenvolvimento. Após a seção introdutória serão traçadas, na segunda seção, as bases acerca do constitucionalismo moderno, responsável pelo estabelecimento do Estado, ao se manifestar como um processo de feição política, social e jurídica destinado à prevalência dos objetivos de limitação ao exercício do poder e promoção das condições de desenvolvimento da pessoa humana. No terceiro segmento, examinar-se-á o constitucionalismo social, responsável pela transformação do Estado de Direito Liberal em Estado Social de Direito. Na quarta seção, devotar-se-á a elucidar os objetivos do Estado Social de Direito, bem como exporá os fatores suscitadores da ausência de efetividade dos direitos sociais, como a influência da crise do Estado Social sobre a eficácia destes direitos. No último segmento, serão desenvolvidos alguns apontamentos em questões que implicam custos dos direitos sociais para o alcance de sua eficácia ao encetar o argumento de que a realização (ou efetivação) dos direitos sociais está assentada na noção de dignidade da pessoa humana e que esta não pode ser relativizada com base em previsões orçamentárias.

Em desfecho a este ensaio, serão esboçadas as conclusões que sintetizarão as ideias expendidas ao longo de toda a investigação, sem a menor pretensão de esgotar o tema.

Todo o arcabouço científico e doutrinário a ser sistematizado ante a proposta de investigação acadêmica consigna-se que será adotado o método sistêmico como método de abordagem do tema, pois em relação ao estudo sobre a erosão das bases do Estado Social de Direito e o impacto na efetivação dos direitos sociais será examinado e elucidado de forma sistêmica ao situá-lo 
dentro do contexto histórico, político, social e constitucional sob um panorama global - estabelecendo conexões entre a realidade factual e as imposições constitucionais em matéria de concretização dos direitos sociais ao se fazer incursões no campo da dogmática geral dos direitos fundamentais.

Para orientar esta investigação, adotam-se três pré-compreensões: (a) o princípio da supremacia da Constituição ao projetar-se não somente sobre as relações de caráter político que se estabelecem entre Estado e cidadão, mas também sobre outras importantes esferas da vida social; (b) a instituição da dignidade da pessoa humana como fundamento do atual Estado Social de Direito ao implicar não apenas o reconhecimento formal e substantivo da liberdade e da igualdade, mas também a garantia de condições mínimas para uma existência digna; (c) as normas definidoras de direitos sociais consagradas e reconhecidas constitucionalmente não são relegadas para o domínio de inócuas declarações: delas devem resultar obrigações ativas para o Estado e uma vinculação para o legislador.

Nessa ótica, comunga-se com a escorreita lição do Jurista e Professor Doutor Juarez Freitas que ao escrever sobre a interpretação sistemática do Direito aduz que em razão da incompletude do conhecimento científico, da modificabilidade da ordem jurídica ao considerar a abertura do sistema jurídico ${ }^{1}$ é preciso escolher a interpretação tópico-sistemática, como processo hermenêutico por excelência, de tal maneira que se compreenda o Direito como totalidade vivificada em contínua interação circular e dialética com o intérprete, ou seja, interpretar uma norma é interpretar o sistema inteiro para além de sua dimensão textual (FREITAS, 2010).

Assim, adota-se como premissa lógica tal modelo interpretativo das normas constitucionais definidoras de direitos fundamentais sociais, visto que em toda relação jurídica haverá sempre a incidência, direta ou indireta, de prescrições constitucionais, razão pela qual conveniente afirmar que qualquer compartimento do Direito encontra-se, por assim dizer, constitucionalizado. Algo que corrobora a ideia de que uma adequada interpretação sistemática precisa ser, de modo insofismável, bem efetuada hermenêutica constitucional (FREITAS, 2010, p.289).

\footnotetext{
${ }^{1}$ Segundo as palavras do Dr. Juarez Freitas, o sistema jurídico deva ser entendido como "uma rede axiológica e hierarquizada topicamente de princípios fundamentais, de normas estritas (ou regras) e de valores jurídicos cuja função é a de, evitando ou superando antinomias em sentido amplo, dar cumprimento aos objetivos justificadores do Estado Democrático, assim como se encontram consubstanciados, expressa ou implicitamente, na Constituição" (FREITAS, 2010, p.63).
} 
A investigação será produto de reflexão crítica, inovadora e inclinada aos valores da ética, da justiça, da moral e da dignidade da pessoa humana nos quais se assentarão todos os seus resultados alcançados.

Cumpre informar a opção pelo sistema completo em relação às citações feitas nas notas de pé de página (rodapé). Observa-se que a primeira citação de uma obra, em notas de pé de página, terá sua referência completa e as subsequentes citações da mesma obra serão referenciadas de forma abreviada (indicação das obras pelo(a) autor(a), título e número da página), conforme as regras estabelecidas pela Associação Brasileira de Normas Técnicas (ABNT). Preferiu-se por trabalhar com as citações no sistema completo para propiciar uma maior facilidade nas consultas, a fim de que não haja necessidade de manejar constantemente a referência no final deste ensaio. Consigne-se que todos os dados das fontes consultadas citadas estarão imediatamente disponíveis à medida que a leitura se desenvolva nesta pesquisa (investigação) empreendida.

A investigação é de cunho bibliográfico, de natureza descritivo-analítica e explicativa (qualitativa), com manejo de vasta literatura jurídica, em especial, a portuguesa, com registros também de fontes doutrinárias consultadas em espanhol, inglesa e brasileira, sempre se concentrando os esforços na tentativa de esboçar uma construção própria para submetê-la à leitura crítica.

Cumpre consignar que se optou pela atual versão da língua portuguesa em conformidade com o Acordo Ortográfico da Língua Portuguesa, assinado em Lisboa, em 16 (dezesseis) de dezembro de 1990, produzindo efeitos a partir de $1^{\circ}$ (primeiro) de janeiro de 2009 na ordem jurídica brasileira (BRASIL, 2008) e 13 (treze) de maio de 2009 na ordem jurídica portuguesa (PORTUGUAL, 2010) com a finalidade de unificar a ortografia de língua portuguesa. Por uma questão de rigor e de coerência ante a opção gráfica indicada, procedeu-se à uniformização global do texto, com a alteração, em relação ao original, de todos os segmentos mencionados neste ensaio de obras portuguesas ao serem adaptados ao acordo ortográfico.

\section{O ESTADO DE DIREITO NO CONSTITUCIONALISMO MODERNO}

O constitucionalismo não se caracteriza como um movimento exclusivo e típico da modernidade, sendo conhecidas as suas manifestações pré-modernas, consubstanciadoras do que se denomina constitucionalismo antigo e medieval (CANOTILHO, 2003, p.1139-1140). 
Por falar nisso, Nicola Matteucci encara a noção de constitucionalismo não como próprio a um momento histórico, mas como um tipo ideal que sujeita a análise crítica das experiências constitucionais ao seu enquadramento, ou não, integrando nele as doutrinas e concepções que se erigiram em derredor das condições prescritivas para instauração de um governo reto ao apresentarse como uma "[...] técnica de la libertad contra el poder arbitrario" (MATTEUCCI, 1998, p.23-34).

Em um sentido mais amplo de Constituição, torna-se possível identificar a presença na Antiguidade de um regime que disciplinava o exercício do poder, caracterizando-se, segundo Maurizio Fioravanti (FIORAVANTI, 2001, p.3031) a noção de Constituição como um grande projeto de conciliação social e política, não se revestindo de caráter unilateral, mas resultando da aptidão da comunidade de manter-se organizada e disciplinada de forma duradoura e harmônica, conforme se dera na polis grega e na res publica romana, detendo a condição de uma ordem política ideal.

Da mesma forma, cabe rechaçar a concepção de que a Idade Média foi a época das trevas ou do eclipse da noção de Constituição, pois nesse período houve o desenvolvimento de várias doutrinas e ideias, além de instituições, que formaram o amálgama fundador do constitucionalismo moderno (FIORAVANTI, 2001, p.33-37).

Foi na Idade Média que se aprofundou o traço essencial que viria impulsionar o constitucionalismo moderno e que, em verdade, é o seu fio condutor, qual seja, a imposição de limitações ao exercício do poder, eis que a Constituição medieval traz intrínseca a limitação aos poderes públicos, ainda que não por uma via dogmática e positivada, mas real e de fato ao configurar-se como uma ordem jurídica de fato.

Além disso, tanto o constitucionalismo antigo como o medieval se firmaram na noção de Constituição mista, tida como um ponto médio, como referencial de equilíbrio que conferia à comunidade política estabilidade. Para Fioravanti (2001, p.63), uma Constituição mista remete a uma comunidade política e social composta e plural, "[...] opuesta a todo intento de uniformización, dispuesta a reconocerse en una ley fundamental común solo porque es consciente del hecho de que esa ley no viene de arriba", mas deriva de pactos e acordos formados pelas partes e segmentos sociais.

Apesar disso, cumpre atentar especificamente para o constitucionalismo moderno, responsável pela afirmação da concepção racional-normativa de Constituição, como vislumbrado por García-Pelayo (2000, p.34-41) em que se 
busca a racionalização e a contenção ao exercício do poder pela positivação de limites e garantias num texto escrito dotado da especial característica da rigidez.

Karl Loewenstein (1965, p.8-9) considera ser impositiva a existência de limites e restrições ao poder em razão do risco intrínseco de que seja exercido abusivamente, justificando-se tanto em interesse dos seus detentores como dos seus destinatários. Desse modo, tanto na história antiga como na moderna, o núcleo do constitucionalismo consiste num "[...] agreed set of fixed rules, binding the power holders and the power address alike, was found to be the most effective device to prevent the abuse of political power by the power holders". 2 E a inscrição de tais regras fixas num documento formal é o que vai compor as constituições, malgrado considerar que também podem advir de costumes e da consciência nacional.

O constitucionalismo moderno é expressão da simbiose de concepções filosóficas, políticas, econômicas e jurídicas que se erigiram contra o exercício arbitrário do poder político pelo Estado absolutista e em prol da liberdade individual, em todas as suas mais plenas manifestações, notadamente as que concerniam à atividade econômica.

Bastos e Britto (1982, p.67) caracterizam as constituições positivadas como decorrentes do constitucionalismo, movimento de cunho político-social destinado a afirmar o primado da liberdade sobre o poder, sendo as constituições o mais autorizado instrumento de limitação e contenção do poder.

Nessa esteira de raciocínio, Canotilho (2002, p.51-52) assinala que o constitucionalismo caracteriza-se como um movimento político, cultural e social, encerrando, ainda, uma teoria normativa da política.

Não se pode definir de forma exaustiva ou fechada o constitucionalismo ao representar uma noção aberta porque pautada pela historicidade constitutiva do seu sentido, revelando-se como um processo de matiz política, social e jurídica destinado à prevalência dos objetivos de limitação ao exercício do poder (inicialmente apenas político ao se expandir em razão de outras manifestações de poder, como o constitucionalismo social, que se opõe ao abuso do poder econômico) e promoção das condições de desenvolvimento da pessoa humana.

Em verdade, não existe um constitucionalismo, mas vários constitucionalismos, ainda que unidos pelo fio condutor para expressarem sempre a tendência de satisfação de uma necessidade de limitação ao exercício do

\footnotetext{
${ }^{2} \mathrm{O}$ texto, em tradução livre, possui a seguinte correspondência para o português: "[...] um acordo sobre regras fixas, vinculando tanto os detentores do poder como aos seus destinatários se mostrou como o meio mais efetivo para prevenir o abuso de poder político por quem o exerça".
}

REVISTA DO DIREITO PÚBLICO, Londrina, v.8, n.2, p.63-90, mai./ago.2013 
poder e da proteção da pessoa humana, variando bastante as concepções que lhe subjazem, a despeito de sempre se voltarem para a adoção de técnicas de contenção e controle ao exercício do poder e para a consagração de direitos tidos como fundamentais.

O constitucionalismo moderno é o responsável pela fundação do Estado de Direito, ainda que, em sua feição inicial, não tenha logrado êxito em conter os poderes do Estado em suas múltiplas manifestações, até porque nesse período histórico o Legislativo não estava jungido à Constituição e, consequentemente, o Estado de Direito longe estava de merecer a qualificação constitucional ao se reduzir, portanto, a um Estado legal ou legislativo. ${ }^{3}$

O Estado de Direito é a forma de manifestação institucional do Estado intrínseca ao constitucionalismo ao ter por desiderato tanto promover a domesticação do exercício do poder político, opondo-se ao absolutismo, como também a proteção da pessoa humana. Daí não se justifica eximir o Estado de Direito de qualquer significação garantista, assimilando simplesmente o Estado de Direito.

E essa domesticação do exercício do poder ocorre pelo próprio Direito ao impor limites, ao instituir a separação de poderes e ao consagrar as contenções derivadas dos direitos fundamentais, inicialmente restritas aos direitos individuais e aos direitos políticos.

A nota típica e mais relevante para caracterizar o Estado de Direito é, portanto, a de que se constitui, tanto quanto o rule of law, ${ }^{4}$ num regime jurídicoconstitucional pelo qual se dá a sujeição do poder político ao Direito.

\section{O ESTADO DE DIREITO NO CONSTITUCIONALISMO SOCIAL}

A luta do constitucionalismo contra o exercício arbitrário do poder é progressiva e contínua, ora com retrocessos indesejados e forçados, ora com vitórias pontuais, porém importantes, ao estarem ao alcance de riscos se os seus resultados não forem persistentemente entrincheirados e blindados.

\footnotetext{
${ }^{3}$ Em outro plano de análise, Jorge Reis Novais (2004, p.20) aduz que o Estado de Direito não irrompe num momento histórico concreta e precisamente delimitado, tampouco surge em todos os países simultaneamente ou por meio de processos idênticos, porquanto o seu advento foi diferenciado no tempo, na forma e nos processos de institucionalização.

${ }^{4}$ No rule of law há o reconhecimento do pluralismo de fontes e a compreensão do processo como momento de construção do Direito voltado ao caso; já no Estado de Direito se sustenta a primazia da lei, que do caso se distancia. A síntese das diferenças entre ambas as noções é dada por Zagrebelsky (2002, p.24-26).
} 
Se o Estado de Direito no constitucionalismo moderno, qualificado como legal e liberal, voltou-se para a contenção ao exercício do poder da administração e do judiciário, tornou-se crucial a necessidade de estender tais limites também ao legislador. E não só ao Estado no exercício do poder político, sobrevindo, da mesma forma, a limitação do exercício abusivo do poder econômico, seja para a preservação do próprio sistema, seja para a superação da Questão Social.

E essa nova luta se estabelece sem que tenha sido integralmente vencida a batalha anterior, agregando-se as dificuldades e tornando ainda mais complexos os desafios postos ao constitucionalismo diante da sua pretensão de erigir um Estado de Direito que seja constitucionalmente adequado ao contexto político, social e econômico.

Destaca-se a passagem de Pablo Lucas Verdú (2007, p.137) ao reconhecer que a institucionalização do Estado de Direito foi e é uma conquista, ao que adere Elías Díaz (1998; p.110) ao referir especificamente ao Estado Social de Direito como uma conquista histórica.

O constitucionalismo social, responsável pela transformação do Estado de Direito Liberal em Estado Social de Direito, continuou com a penhorada crença na racionalidade, bondade e legitimidade do legislador, apresentando-se, também, como Estado Legal. Todavia, essa legalidade, pelas próprias características do Estado Social, teve de ser transferida ao Poder Executivo ao descortinar outra série de problemas que antes não se puseram.

O Estado Social de Direito será, portanto, um Estado Legal, só que não apenas do Parlamento, mas também do Executivo, tornando os direitos fundamentais ainda mais dependentes do legislador, esteja ele legitimado democraticamente, esteja ele legitimado finalisticamente. No primeiro caso, tem-se o Parlamento; no segundo, o Executivo. A supremacia do Legislativo cede ante a hipertrofia do Poder Executivo.

A luta preconizada, no entanto, contrariamente do que ocorrido no constitucionalismo liberal, não se eleva contra o Estado, mas, como afirmado por García-Pelayo, efetiva-se mediante o Estado, por um Estado que esteja capacitado a exercer as suas funções interventivas, a desenvolver políticas públicas e a prestar serviços públicos que possibilitem a redistribuição da riqueza e a justiça social. ${ }^{5}$

\footnotetext{
${ }^{5}$ Homem (2001, p.48) em referência à obra de John Rawls, ao preocupar-se com as questões do conteúdo da justiça, destaca a importância de pensar os direitos fundamentais como matéria da justiça, a qual estabelece o modo pelo qual as instituições sociais distribuem os direitos e deveres fundamentais e determinam a partilha dos benefícios da cooperação social.
} 
Os fundamentos de legitimidade do Estado estavam fortemente firmados nos princípios da igualdade e da solidariedade, exprimindo o ligame social em que se funda a socialidade ínsita ao Estado de Direito do constitucionalismo social, erigido diante da gravidade da Questão Social, ${ }^{6}$ marcada pela miséria e pelo pauperismo excludente causado pelo capitalismo industrial monopolista.

Embora não se diriga contra o Estado, mas vise a atuar por meio dele, o Estado Social de Direito terá a sua eficácia condicionada, dentre outros fatores, pela contínua dependência do legislador quanto aos novos direitos que, incorporados às constituições, integram uma nova dimensão de direitos fundamentais: os direitos sociais.

Naqueles Estados em que o processo democrático foi suficiente para impelir à efetiva institucionalização das promessas de emancipação social decorrentes da promoção dos direitos sociais, a questão atinente à interpositio legislatoris não foi tão sentida como condição para a realização de tais direitos; em outros, notadamente naqueles que possuem uma democracia incipiente e um povo ainda não integrado aos espaços público-decisórios, foi um dos principais obstáculos.

\subsection{A questão social e o constitucionalismo social instituidor do Estado Social}

O sistema econômico capitalista institucionalizado na ordem econômica do ser mediante a afirmação jurídica das liberdades, da igualdade formal, da propriedade privada e da segurança, valeu-se do mercado como instância de regulação das relações entre os agentes econômicos.

No constitucionalismo moderno, de matriz liberal, operou-se forçosamente um tratamento jurídico igual para todos, ao fundamento de que todos os homens, como indivíduos dotados de razão e discernimento, devem governar e determinar

\footnotetext{
${ }^{6}$ De acordo com o magistério de José Luís Bolzan de Morais, o constitucionalismo social traz consigo o reconhecimento constitucional desta questão social que advém das transformações operadas pelas revoluções industriais, pelo novo modelo de produção (fabril) e pela emergência de uma nova categoria social - o proletariado ou as classes operárias (MORAIS, 2008, p.177).

$\mathrm{Na}$ verdade, esta questão social vem apresentada constitucionalmente sob os inéditos direitos sociais - de igualdade ou direitos econômicos, sociais e culturais (DESC) - que em tudo diferem dos direitos de liberdade (civis e políticos), em particular por exigirem uma maior e mais qualificada intervenção estatal, bem como a elaboração de políticas públicas prestacionais para a sua satisfação, o que faz desviar o foco das atenções da esfera legislativa do Estado para o ambiente da atividade executiva. Não basta apenas legislar, é necessário assegurar a usufruição dos direitos constitucionalizados por intermédio de políticas públicas implementadoras dos conteúdos reconhecidos pelo legislador.
} 
a si próprios; contudo, esse princípio de autodeterminação dos indivíduos no âmbito da sociedade, associado ao da autorregulação do mercado, conduzida pela mão invisível, mostraram-se falhos, olvidando a tendência natural do capitalismo para a concentração do capital e, consequentemente, formação de oligopólios e monopólios que possuíam poder econômico.

Da mesma forma, no âmbito das relações sociais, o constitucionalismo moderno erigiu um sistema de proteção voltado para aqueles que detinham a propriedade; pela propriedade seria possível prover a si próprio e a sua família, superando os riscos pertinentes tanto da segurança civil como da segurança social, pois “"...] os indivíduos proprietários podem proteger-se por si mesmos, mobilizando seus próprios recursos, e podem fazê-lo no quadro legal de um Estado que protege esta propriedade", o que identifica uma segurança garantida. (CASTEL, 2005, p.22).

Com efeito, a propriedade não era um direito passível de aquisição e fruição por todos os indivíduos igualitariamente, seja aquela caracterizada como propriedade individual, pela qual se busca o consumo para a satisfação das necessidades básicas e vitais, de caráter existencial, como também a propriedade dos bens de produção, conformando o capital que era detido apenas por alguns membros da sociedade que o utilizava no desempenho da atividade econômica por ele escolhida.

Se a propriedade era um direito fundamental, não figurando apenas como relevante no âmbito da ordem econômica, consistia justamente na sua condição de ser o substrato pelo qual se poderia angariar a segurança social e programar o futuro; todavia, o constitucionalismo moderno foi insensível, como expressão dos ideais burgueses, àquilo que seria a condição dos não-proprietários. Como salienta Robert Castel (2005, p.28), tal questão não compôs o quadro de reflexão do constitucionalismo moderno e muito menos do ideário que deu ensejo à conformação da ideologia da modernidade.

Tanto a situação de insegurança dos não-proprietários à margem do mercado de trabalho, que não detêm capital e nem bens individuais suficientes à mantença, precisando do salário para o provimento de suas necessidades, como a dos trabalhadores assalariados remete à pobreza e à exclusão social.

Consigna-se que a questão social não qualifica simplesmente uma situação de grave pobreza em que se encontre expressiva parte da população; apresentase como uma forma de designação dos efeitos do funcionamento econômico específico sobre a maneira pela qual os indivíduos se encontram perturbados ou ameaçados quanto ao modo de inserção no trabalho e à capacidade de produzir e obter as condições materiais de que necessitam. 
Isso posto, pode-se dizer que o Estado Social de Direito surgiu como resposta às crescentes necessidades que a sociedade não podia suprir por si só e como resposta a outro modelo de Estado erigido com a pretensão de suprir tais necessidades: o Estado socialista soviético. A consagração do Estado Social de Direito teve forte influência da Doutrina Social da Igreja, ${ }^{7}$ já que significou solução reformista para os problemas sociais, sem ruptura com o sistema capitalista, podendo-se dizer que, tendo sido impulsionado pela "ameaça socialista", adotou solução social que preservou a liberdade individual e a propriedade privada. Por outro lado, o elemento democrático buscou afastar da memória europeia as experiências autoritárias que vigeram, em boa parte dos países, até o fim da Segunda Guerra Mundial.

Conforme explica Otero (2007, p.335), a influência do magistério da Doutrina Social da Igreja constitui forte contributo para a instituição de um Estado Social, pois desde os finais do século $\mathrm{XIX}^{8}$ denunciava a incapacidade do liberalismo em resolver a questão social ao combater o individualismo selvagem e implementar a justiça social por meio de um modelo de bem-estar, determinando que as autoridades públicas promovam o auxílio à família, o desenvolvimento da função social da propriedade privada, a defesa dos trabalhadores e da sua dignidade contra os abusos decorrentes de uma exploração econômica desenfreada à luz da livre concorrência.

\subsection{Surgimento e desenvolvimento do constitucionalismo social}

O antecedente histórico do constitucionalismo instituidor do Estado Social se apresenta pela preocupação com a condição social do homem, sobretudo pelas pressões das classes trabalhadoras e dos movimentos teóricos e políticos de contestação do funcionamento econômico capitalista com o fim de conter o arbítrio do poder econômico, governado pelo lucro e pela acumulação de capital.

As primeiras referências aos direitos sociais projetam-se na Inglaterra ante o impacto que a questão social ensejou, ocorrendo mais cedo do que na

\footnotetext{
${ }^{7}$ Registra-se o escólio de Novais (2004, p. 56) para quem a dignidade da pessoa humana, um dos fundamentos do Estado Social de Direito, teve inegável influência do cristianismo em sua origem. ${ }^{8}$ Foi por meio da Carta Encíclica Rerum Novarum, de 15 de maio de 1891, o Papa Leão XIII (18781903), insurgindo-se contra a situação de exploração dos operários e a pobreza gerada pelo liberalismo e, por outro lado, contra as ideias socialistas contrárias à propriedade privada, procede, segundo os princípios da justiça e da verdade, à edificação da doutrina social da Igreja ao evitar que a direção do movimento social ficasse restrito dos partidos revolucionários (OTERO, 2007, p.292).
} 
Europa continental em razão do prematuro desenvolvimento inglês ao justificar a edição da Poor Law (BITENCOURT NETO, 2010, p.42-44).

As Poor Law inglesas identificadas no século XVII, especificamente no ano de 1601, tiveram o importante papel de oficializar ou consolidar a formalização da substituição da contribuição voluntária pela obrigatória com o fim de destinar recursos para a assistência pública aos necessitados em que o dever moral ou religioso é substituído pela obrigação legal (BITENCOURT NETO, 2010, p.44).

Este sistema foi alterado em 1834 com o Poor Law Amendment Act, cingindo-se a assegurar as condições existenciais daqueles que apresentassem alguma incapacidade para a atividade laboral, como idade avançada ou doença (DANTAS, 2009, p.192).

Já no século XX, com origens ainda no transcurso do século XIX, observase que o próprio Estado Liberal transmutou-se substancialmente ao assumir a cariz de Estado Social, conceito aqui utilizado em sua acepção genérica, suportado em um novo constitucionalismo - agora social -, este identificado histórica e privilegiadamente com as Constituições mexicana de 1917 e de Weimar de 1919 - apresentadas, de regra, como marcos históricos -, vindo em resposta ao novo tratamento do que temos delineado de questão social, a qual deixa de ser um "caso de polícia" para tornar-se um caso de políticas públicas (sociais), com o objetivo de enfrentamento dos dilemas da escassez (MORAIS, 2008, p.177).

A ideia assentada quanto à real formatação do que seja o Estado Social é a de que este tem mantido a natureza de solução de compromisso, que se traduz na adaptação das estruturas sociais e políticas da sociedade capitalista aos ventos da história e às exigências do tempo histórico. ${ }^{9}$

\section{OS OBJETIVOS DO ESTADO SOCIAL DE DIREITO}

A crise do capitalismo liberal, seja pelo seu caráter autodestrutivo, seja pelo advento da questão social, demonstrou a inconsistência do mercado regular a si próprio. A teoria econômica clássica não previu o desvirtuamento e o

\footnotetext{
${ }_{9}$ Nunes (2011, p.32-33) em magistral lição, pontifica que a estabilidade da ordem burguesa suscetível a ameaças e que a ruptura da sociedade capitalista somente poderia ser evitada (adiada) a partir do Estado, o Estado capitalista ao assumir a "veste" de Estado Social continuou a assegurar a consolidação da ordem burguesa ao garantir a coesão social, isto é, o equilíbrio do sistema econômico e social, condição essencial para que as suas estruturas se mantenham, nomeadamente a estrutura de classes e o estatuto da classe dominante.
} 
desequilíbrio que havia na suposta racionalidade econômica em razão da acumulação de capital conducente ao poder econômico. E como quem detém o poder tende a dele abusar, houve a sucessão de deficiências do modelo liberal acima anunciadas.

O constitucionalismo social irá se opor ao poder econômico, tentando domesticar o mercado para dirigir a atividade econômica e a produção de riqueza para finalidades comunitárias tidas por relevantes, visto que exprimem o ligame social.

Para a reforma e transformação do capitalismo, entretanto, não seria suficiente a afirmação constitucional dos princípios e dos direitos que lhe davam sustentação, pois não bastaria institucionalizar as condições e os pressupostos de livre funcionamento do mercado; seria premente não apenas fazer com que o mercado existisse, mas que a atividade econômica fosse direcionada para a realização de determinadas finalidades comunitárias, que deveriam ser de relevo constitucional, notadamente as relacionadas com a promoção de uma mínima condição existencial de vida digna, o que remetia à imposição de tarefas do Estado, como também à sua vinculação à garantia, à proteção, à promoção e à satisfação dos direitos fundamentais, em especial dos direitos sociais.

Como decorrência da institucionalização do Estado Social, com a constitucionalização da ordem econômica e mediante o seu amadurecimento com o pós-Guerra, Luño (2005, p.232-235) sustenta os traços que devem qualificá-lo, consistentes na(o): (a) afirmação da necessidade de coexistência entre o princípio democrático e os princípios sociais e o Estado de Direito; (b) superação da distinção entre sociedade civil e Estado ao conferir a este a tarefa de intervir sobre o domínio econômico, com a responsabilidade de transformação da ordem econômica e social, refreando o poder econômico; (c) superação da dimensão negativa dos direitos fundamentais, impositiva da abstenção do Estado, que passam a ser instrumentos jurídicos de controle da ação estatal, destituídos de caráter meramente programático (entenda-se como programático a ausência de caráter jurídico); (d) pluralismo político, e; (e) persistência das garantias jurídicas do Estado de Direito. Em verdade, tais elementos já estão muito próximos de acarretar a conversão do Estado Social de Direito no que se concebe como Estado Democrático de Direito por consubstanciar um Estado Constitucional que abriga a todos os caracteres enumerados por Pérez Luño.

Com efeito, o direcionamento do Estado Social de Direito para determinados objetivos de caráter social consubstancia a própria essência do conteúdo material do Estado de Direito que lhe é referido, agregando-os aos direitos fundamentais. 
Os objetivos e finalidades do Estado, constitucionalmente consagrados, são a representação jurídica do sentido da solidariedade social ao ensejar a integração e o sentimento de pertença, de que provém a necessidade de superação da separação entre sociedade e Estado.

Häberle (2002, p.182) direciona os objetivos do Estado Social à consecução da justiça social, incumbindo-lhe, pois, planejar, dirigir e distribuir as prestações sociais em consonância com a capacidade de sustentação da sociedade.

Verdú (2007,p.104) expressa que o núcleo da política social do Estado Social de Direito é a repartição dos benefícios sociais, exaltando a importância do objetivo de redistribuição da riqueza produzida ao remeter, portanto, à justiça social. Para isso, ressalta acertadamente a função social do tributo, pois a dita reserva orçamentária, consistente no condicionamento financeiro da capacidade de atuação do Estado pode ser limitada a partir da percepção de que o tributo ao constituir expressão de solidariedade social, impõe determinados deveres fundamentais ao Estado, concernentes à alocação dos recursos arrecadados.

Dessa forma, para fins de explicitação dos modelos de Estado Social, uma variação dos objetivos fundamentais pode propiciar uma modificação estrutural da sua compostura, caracterizando como um Estado Social protetor ou securitário, um Estado Social redistributivo, um Estado econômico, ${ }^{10}$ ou, ainda, um Estado Social assistencialista, a depender das direções assinaladas para as políticas públicas.

\subsection{O Estado Social de Direito e o problema da falta de efetividade dos direitos sociais}

O Estado Social de Direito, em sua primeira manifestação, antes de eclodir a Segunda Guerra Mundial, mantinha-se subordinado à noção de legalidade, persistindo a mesma redução positivista de direito à lei. Perdurava, ainda, o dogma do legislador racional, reforçado pela adoção acrítica dos postulados científicos do positivismo jurídico.

Prevalecia, ainda, a lei sobre a Constituição, principalmente no que respeita aos direitos sociais, em razão do que se pode identificar que a concretização

\footnotetext{
${ }^{10}$ Nunes $(2011$, p.32) refere ao Estado econômico como respeitante à intervenção promotora e financiadora da acumulação e da produção privada, integrando, também, o caráter redistributivo e planificador. No caso, utiliza-se a expressão Estado econômico apenas no que respeita à atuação do Estado sobre o mercado para fomentar o desenvolvimento e evitar as crises conjunturais.
} 
efetiva e existencial dos programas atinentes ao Estado Social de Direito, com a realização das funções estatais ao visar à consecução dos novos objetivos estabelecidos pela Constituição econômica contida nas constituições sociais, nessa época do entreguerras mais dependia do processo democrático e das pressões e exigências populares do que da operatividade e efetividade do texto constitucional.

Da análise expendida, podem-se inferir duas consequências. A primeira consiste na verificação empírica de que os Estados Sociais que se estabeleceram em países em que vicejou a democracia foram mais efetivamente implementados, como ocorrido na maioria dos países europeus; naqueles em que houve hiatos democráticos, mesmo a partir do pós-Guerra, o Estado Social foi incompletamente realizado ou desvirtuado ao engendrar a ampliação das funções do Estado sobre a ordem econômica, mas sem que houvesse a tradução na substancial melhoria das condições sociais ou no provimento dos níveis mínimos de emancipação social. Saliente-se que, no que refere aos direitos sociais, mesmo após o advento e a consolidação da jurisdição constitucional, houve a continuidade da sua sujeição ao advento da lei ulterior que o regulamente, porquanto não se sustentava a possibilidade da justiciabilidade de tais direitos enquanto não disciplinados por lei. ${ }^{11}$

A outra consequência foi de que não se admitiria a continuidade dessa frustração normativa dos direitos sociais, empreendendo uma verdadeira erosão da consciência constitucional, pois, como salienta Loewenstein (1965, p.161) as constituições - até então - tinham falhado quanto ao objetivo de estabelecer uma ordem social resguardada de crises e maiores riscos, sofrendo uma crise que refletiria a própria vicissitude do Estado Democrático (ou Constitucional).

\footnotetext{
${ }^{11}$ Cabe registrar a lição de Correia (2004, p.969-970) ao entender que a divisão dos direitos fundamentais, da Constituição portuguesa, nas categorias Direitos, Liberdades e Garantias (DLG) e Direitos Econômicos, Sociais e Culturais (DESC) exerce impacto diretamente na autonomia do legislador e na separação e interdependência dos poderes quanto às questões relacionadas a estes direitos. Os âmbitos de autonomia do legislador para densificar o conteúdo de cada direito e a delimitação entre o campo reservado à atuação do legislador e o campo franqueado ao controle jurisdicional expressam claramente o impacto referido. Para os DLG, é sempre possível determinar, com fulcro na norma constitucional - interpretada no contexto sistemático constitucional e da Declaração Universal dos Direitos Humanos -, um conteúdo essencial que limita a autonomia do legislador e garante a justiciabilidade por força do art. $18, \S 1^{\circ}$ da CRP/1976. Quanto aos DESC, considerando não haver limitação fundada em uma densidade essencial autônoma dada pela Constituição, ao legislador abre-se uma liberdade de conformação política, no exercício da qual aprecia as possibilidades financeiras e econômicas, balizado apenas pelo dever de manter o nível global de proteção já consagrado legislativamente para os DESC como um todo.
} 
Como as constituições não poderiam conviver com essa reputação e a insensibilidade pelo distanciamento entre o seu texto e a realidade, visto que acarretaria a frustração da sua dimensão libertária e o afrouxamento dos vínculos sociais pelo debilitamento da solidariedade que fundamenta tanto o Estado Social como os direitos fundamentais, passaram elas a dispor sobre a própria eficácia dos direitos fundamentais, autointitulando-os como de aplicabilidade imediata. ${ }^{12}$

Quanto à efetiva realização dos direitos sociais, identifica-se a ausência de políticas públicas como responsável pela não efetividade dos direitos sociais. É importante considerar que a não decisão é política pública. Não é somente a decisão que produz política, mas também a não decisão, pois esta cumpre objetivos e satisfaz interesses. Como o Estado é estruturalmente dependente da prosperidade econômica dos capitalistas, uma vez que precisa se legitimar perante a população, ele vai apresentar uma seletividade decisória. Por isso, para o estudo e compreensão da efetividade dos direitos sociais é importante considerar política pública não somente o que as autoridades públicas decidiram, mas também o que elas não decidiram.

Os direitos sociais, como quaisquer outros direitos fundamentais, possuem custos financeiros. ${ }^{13}$ Seu exercício depende de recursos que são escassos. ${ }^{14}$ Em torno desses recursos há uma pluralidade de agentes interessados, requerendo do Estado políticas que satisfaçam suas reivindicações. Como a sobrevivência do setor público depende mais de alguns poucos cidadãos do que da maioria, então a alocação desses recursos privilegiará mais esses poucos cidadãos do que a maioria. Há uma seletividade estrutural dos interesses por parte das instituições públicas.

\footnotetext{
${ }^{12}$ Sarlet (2007, p.275-276) ao examinar o contexto da experiência constitucional brasileira ao adentrar mais na seara acerca da aplicabilidade imediata pelo teor do artigo $5^{\circ}$, $\S 1^{\circ}$ da CRFB/1988 que traz referência expressa a direitos e garantias fundamentais, o mencionado jurista sustenta que tal aplicabilidade imediata se estende não somente aos direitos arrolados no artigo $5^{\circ}$ ao 17 (incluindo aqui os direitos sociais), como também dos localizados em outras partes do texto constitucional e nos tratados internacionais.

${ }^{13}$ Segundo lição de Loureiro $(2010$, p.56, 61), todos os direitos, quer sejam direitos de liberdade, quer direitos sociais, econômicos e culturais possuem custos e que a Constituição não pode ignorar o contexto, não se afastando do "colorido vivificante da realidade".

${ }^{14}$ Em seu aclamado e atualizado Manual de Direito Constitucional (vol. IV), Miranda (2012, p. 484) leciona, em síntese, que ao serem abundantes as normas e escassos os recursos poderá resultar a conveniência de estabelecer diferentes tempos, graus, e modos de efetivação dos direitos sociais. Se estes não puderem ser tornados plenamente operativos em certo momento ou para todas as pessoas, então haverá que determinar com que prioridade e em que medida deverão ser. E arremata ao consignar que "[...] o contrário redundaria na inutilização dos comandos constitucionais: querer fazer tudo ao mesmo tempo e nada conseguir fazer".
}

REVISTA DO DIREITO PÚBLICO, Londrina, v.8, n.2, p.63-90, mai./ago.2013 
Por isso, os outros interesses estarão condicionados à reserva do possível. Este princípio surge na Alemanha, numa época em que o Estado começa a sentir que é limitada a sua capacidade de gastos e propõe que certos direitos sociais sejam ponderados com outros direitos fundamentais (como o da competência orçamentária do legislador) (CUNHA FILHO, 2007, p.476). A principal função da cláusula reserva do possível dentro do quadro geral das atividades do Estado capitalista é limitar os gastos do poder público em áreas que não sejam prioritárias. Eram áreas de investimentos sociais que ameaçavam o capitalismo. Nestes tempos de reformas neoliberais as políticas públicas (sociais) quase têm-se limitado ao assistencialismo contra todos os objetivos constitucionais pretensamente realizáveis para a área social, a conjuntura econômica oferece nada mais que paliativos.

Expostas essas questões, a verdade é que a chamada crise do Estado Social ${ }^{15}$ - a crise de se querer dar mais do que possui - ou, na fórmula de João Carlos Loureiro, o insustentável peso do não-ter, só pode ser resolvida a partir de uma nova compreensão da socialidade, que envolva, sobretudo, a adoção de práticas sustentáveis (LOUREIRO, 2010, p.45-138).

Reporta-se à lição de Caupers (2010, p.45) segundo o qual o grande desafio que o Estado Social hoje enfrenta é o da sua própria sobrevivência e que os seus pressupostos de natureza política, ideológica, econômica e social estão claramente postas em crise.

Ora, o Estado Social exige - o que constitui o seu ícone - uma proteção adequada contra os riscos e infortúnios sociais como, por exemplo, doença, velhice e desemprego. A manutenção de tal proteção custa dinheiro ao pressupor um nível mínimo de financiamento público.

O financiamento do Estado Social depende, entre outros fatores, de certo equilíbrio entre a população ativa (contribuinte) e a população inativa (beneficiária); se este equilíbrio se altera, reduzindo o número de ativos por cada inativo, a consequência inevitável é a degradação da proteção (segurança) social ao se observar a adoção de políticas de reformas previdenciárias como a elevação da idade mínima para a aposentadoria, ampliação do tempo de contribuição para os institutos de segurança (previdência) social, redução das pensões, corte nos seguros (subsídios) de desemprego etc.

Isso não ocorreria se aumentassem os encargos sobre a população ativa (os contribuintes), mas esta solução apenas é factível dentro de certos limites e

${ }^{15}$ Conforme pontifica Loureiro (2010, p.18), a crise é uma súmula de crises e é curto e míope reduzila a uma dimensão econômico-financeira. 
só funcionaria num âmbito temporal limitado ao se exigir que a economia alcançasse expressivas taxas de crescimento capaz de absorver o desemprego e melhorar as contribuições ao sistema de segurança social.

\subsection{A tensão entre inclusão e exclusão social}

O Estado Social não se autonomiza do seu ambiente liberal - sobretudo do seu núcleo econômico (liberalismo/capitalismo) -, tanto é que ele vem dependente desta relação de base construída ante o reconhecimento das conquistas sociais e dos interesses do próprio capital, em um pêndulo permanentemente tensionado.

Ademais, a lógica do atual modelo capitalista (neoliberalismo) ao reacender o laissez-faire político-econômico por defender a absoluta liberdade de mercado, inclusive defender o afastamento de qualquer política social visto ser considerada antinatural, para além de improfícua, pois poderia retardar o processo genuíno da sociedade em direção ao progresso civilizacional. Tal formatação ideológica incorreria no chamado darwinismo social (MENEZES, 2008, p.29-32) pois o destino dos pobres ou dos excluídos do acesso dos bens econômicos indispensáveis estava, então, desde logo traçado, visto que na luta pela conservação da vida só os melhores adaptados tinham possibilidades de sobreviver e prosperar (o sucesso e o poder das classes abastadas confirmamno).

Dessa forma, deve-se reconhecer que o Estado Social não abandona sua origem, mas apenas refrea as tensões de suas crises. E o faz por meio de políticas públicas compensatórias de carências, desde que isto não signifique a negação dos fundamentos de suporte do núcleo econômico do liberalismo - o capitalismo - que vem recompensando com a socialização dos custos de infraestrutura econômica, de higidez para o trabalho e de um mercado consumidor em expansão, entre outros fatores.

Exposto de outro modo, o Estado Social não apenas convive, mas admite e incorpora uma relação de inclusão e exclusão em níveis distintos, mas intransponíveis. Para haver inclusão um certo nível de exclusão continua sendo admitido. Indaga-se: quanta inclusão seria possível ou, ao contrário, quanta exclusão se toleraria, mantendo-se o Estado Social?

A experiência histórica tem demonstrado níveis bastante distintos. Ao se observar, sobretudo para os âmbitos de promoção social nos países nórdicos (Dinamarca, Finlândia, Islândia, Noruega e Suécia), Canadá, Espanha e Portugal 
constatam-se diferenças entre eles. No entanto, mesmo no mais exitoso deles, os elementos fundantes da economia liberal permanecem assegurados: propriedade privada, apropriação do lucro etc.

O que se quer dizer com isso é que há que se reconhecer que neste Estado Social ainda se convive com a aceitação de certo nível de exclusão e que em seu arranjo a garantia da vida digna não "vale" para todos ou acontece em níveis distintos. Esta é uma marca inafastável do modelo econômico capitalista ao contaminar o arranjo político do Estado Social.

\section{OS DIREITOS SOCIAIS E OS OBSTÁCULOS À SUA EFETIVAÇÃO, NOTADAMENTE NA CONDIÇÃO DE DIREITOS EXIGÍVEIS: ALGUNS APONTAMENTOS}

O fato de os direitos sociais na condição de direitos fundamentais terem por objeto prestações estatais vinculadas diretamente à destinação, distribuição (e redistribuição), bem como à criação de bens materiais, aponta-se, em tal caso, para sua dimensão economicamente relevante. Os direitos de liberdade (civis e políticos), caracterizados como direitos de defesa ao se dirigirem a uma conduta omissiva, por serem direitos subjetivos, são geralmente considerados destituídos desta dimensão econômica, visto que o bem jurídico que protegem (vida, intimidade, propriedade, liberdades etc.) pode ser assegurado - como direito subjetivo exigível em juízo - independentemente das circunstâncias econômicas ou, pelo menos, sem a alocação direta, por força de decisão judicial, de recursos econômicos. De qualquer maneira, é preciso que se deixe consignado que a referida "irrelevância econômica" dos direitos de defesa não dispensa alguns comentários pertinentes.

Todos os direitos fundamentais são, de certo modo, sempre direitos positivos, ou seja, tanto os direitos de defesa (de liberdade), como os direitos sociais exigem, para sua tutela e promoção, um conjunto de medidas positivas por parte do poder público e que sempre abrangem a alocação significativa de recursos materiais e humanos para sua proteção e efetivação de uma maneira geral. Assim, não há como negar que todos os direitos fundamentais possam implicar um custo, de tal sorte que esta circunstância não se restringe aos direitos sociais.

A efetivação e eficácia dos direitos sociais somente será possível caso se aloque algum recurso ao depender, no entanto, da conjuntura econômica, já que aqui está em causa a possibilidade de os órgãos jurisdicionais imporem ao poder público a satisfação das prestações reclamadas. 
Averbou-se que o Estado possui limitada capacidade de dispor sobre o objeto das prestações reconhecidas pelas normas definidoras de direitos fundamentais sociais, de tal sorte que a limitação dos recursos constitui em limite fático à efetivação desses direitos. ${ }^{16}$

Ante a problemática colocada pelos que apontam para um custo dos direitos, por sua vez indissociável da assim designada reserva do possível, a crise de efetividade vivenciada com cada vez maior agudeza pelos direitos fundamentais de todas as dimensões (ou gerações) está diretamente conectada com a maior ou menor carência de recursos disponíveis para o atendimento das demandas em termos de políticas públicas (sociais). Com efeito, quanto mais diminuta a disponibilidade de recursos, mais se impõe, portanto, uma deliberação responsável acerca de sua destinação, o que nos remete diretamente à necessidade de se buscar o aprimoramento dos mecanismos de gestão democrática do orçamento público, assim como do próprio processo de administração das políticas públicas em geral, seja no plano da atuação do legislador, seja na esfera administrativa, o que diz respeito também à ampliação do acesso à justiça como direito a ter direitos capazes de serem efetivados e, além disso, requer o diálogo em torno da necessidade de evitar interpretações excessivamente restritivas quanto a efetivação, realização dos direitos sociais. ${ }^{17}$

Por isso, os direitos sociais, diferentemente dos direitos de liberdade, os quais estão baseados na igualdade formal, são direitos a níveis mínimos de desenvolvimento, voltados a reduzir as desigualdades materiais. A função de impulso e a natureza condutora do princípio da igualdade faz com que as leis e as políticas públicas, destinadas à efetivação dos direitos sociais, sirvam como

\footnotetext{
${ }^{16}$ Nabais (2007, p.176-177) assevera que todos os direitos (abrangidos aí os clássicos direitos de liberdade e os direitos sociais) não são autorrealizáveis, bem como não podem ser protegidos num Estado falido ou incapacitado ao implicar, segundo ele, a cooperação social e a responsabilidade individual e que todos os direitos fundamentais devam ser vistos como "[...] liberdades privadas com custos públicos". E aduz que os custos dos direitos sociais se concretizam em despesas públicas com imediata expressão na esfera de cada um dos seus titulares, uma esfera que assim se amplia na exata medida dessas despesas.

17 Não é diferente a posição de Miranda $(2012$, p.474-475, 484) ao aduzir que, apesar dos circunstancialismos econômico-financeiros sobre o Estado e sobre a entidades públicas recai a tarefa fundamental de promover a efetivação dos direitos sociais ao constituir base objetiva de ordem constitucional. E, segundo o expoente jurista, sobressaem diretamente as incumbências de promover o aumento do bem-estar social e econômico e da qualidade de vida das pessoas, em especial, das mais desfavorecidas, de promover a justiça social, de assegurar a igualdade de oportunidades e operar as necessárias correções das desigualdades na distribuição da riqueza e do rendimento etc. E arremata ao ensinar que ante os fatores econômicos ou sob o princípio de sustentabilidade financeira "[...] o conteúdo essencial de todos os direitos deverá sempre ser assegurado, e só o que estiver para além dele poderá deixar ou não de o ser em função do juízo que o legislador vier a emitir sobre a sua maior ou menor relevância dentro do sistema constitucional e sobre as suas condições de efetivação".
} 
meios de aperfeiçoamento da isonomia, em sentido substancial, pela eliminação de desigualdades fáticas.

Nesta senda, a exigência da efetivação, da realização dos direitos sociais se assenta na dignidade da pessoa humana, valor prévio ao Estado, mas reconhecido como norma do ordenamento, com caráter de princípio que impõe preservação, promoção destes direitos, proíbe condutas estatais contrárias à sua salvaguarda e busca compelir ações estatais necessárias à concretização dos direitos sociais.

A dignidade humana ao constituir um valor absoluto por se assentar na premissa de que o ser humano é um fim e não meio, abrange aquele mínimo irremissível inerente a qualquer direito fundamental ao abarcar, inclusive, os direitos sociais. Ademais, consubstancia a exigência de prestações do Estado que afiancem os pressupostos materiais mínimos para a preservação da vida e a inclusão na sociedade, bem como a proteção em relações privadas, em que se saliente sua situação de vulnerabilidade ( $\mathrm{p}$. ex., relações de trabalho, consumo etc.).

Os direitos sociais não são apenas tarefas prestacionais que vinculam o Estado, eles são também deveres fundamentais que responsabilizam cada um perante os restantes membros da sociedade: em cada ser humano há um direito e um dever fundamental de raiz social. A solidariedade é, afinal, o nome da dignidade humana em sociedade. A dignidade de cada ser humano nunca será perfeita se ao seu redor existirem seres humanos que vivem sem dignidade (OTERO, 2012, p.45).

Logo, não seria possível relativizar a noção de dignidade com base em previsões orçamentárias (NUNES JÚNIOR, 2009, p.114, 190).

\section{CONCLUSÃO}

Apresentados os pontos cardeais da investigação e reflexão empreendidas com o intuito de verificar as razões do processo de erosão das bases do Estado Social ao sustentar a ideia de que é possível conviver ou conciliar a realização, efetivação dos direitos sociais em situações de insustentabilidade financeira ao se impor, portanto, uma deliberação responsável acerca da destinação dos recursos públicos sob o aperfeiçoamento dos mecanismos de gestão democrática do orçamento estatal, em que a imposição de efetivação dos direitos sociais se estriba na dignidade da pessoa humana com vistas na concretização da justiça social. Logo, sem desconhecer os 
riscos inerentes às sínteses, expõem-se, esquematicamente, nas linhas abaixo, as ideias essenciais que indicarão o arremate do pensamento desenvolvido ao longo deste estudo.

1. A evolução do constitucionalismo se exprimiu concomitantemente com a sua expressão na estruturação do Estado de Direito ao ter por fundamento comum a ampliação e busca de efetividade dos direitos fundamentais.

2. O Estado de Direito é, pois, entendido inicialmente como Estado Legal e Estado Liberal ao ser conduzido pelo constitucionalismo social ao Estado Social.

3. A Questão Social, como se depreendeu, não se caracteriza por um conjunto de problemas sociais que são coetâneos e próprios de determinadas épocas, mas se revela como uma decorrência estrutural do sistema econômico capitalista, fundado na economia de livre mercado, dirigida pelo poder econômico, governado pelo lucro e pela acumulação de capital. Tratase de um problema acerca das próprias estruturas das relações sociais, derivadas da adoção do sistema econômico capitalista ao exprimir uma autorrepresentação da coletividade como sociedade, em que os vínculos sociais são frouxos e efêmeros, conduzidos os indivíduos pelos intentos egoísticos próprios do individualismo. Constitui uma designação dos efeitos do funcionamento econômico sobre a maneira pela qual os indivíduos se encontram perturbados ou ameaçados quanto ao modo de inserção no trabalho e à capacidade de produzir e obter as condições materiais de que necessitam.

4. Assim, diante da Questão Social, impôs-se o restabelecimento da coesão social mediante o esforço comunitário decorrente da solidariedade que, como resultante da autocompreensão da coletividade como comunidade, migrou para os textos constitucionais ao proporcionar fundamentação éticoconstitucional ao Estado Social. Em razão do pauperismo, da exclusão e da marginalização, surge como resposta o pacto comunitário que atribui ao Estado tarefas quanto à ordem econômica, destinada a compensar as deficiências do capitalismo liberal ou mesmo transformar o sistema econômico vigente.

5. Todos os objetivos do Estado Social exprimem e se fundamentam na solidariedade social e direcionam-se, por distintas vias, à proteção, à garantia, à promoção e à satisfação das condições pertinentes à existência digna. E não só quanto ao que refere ao mínimo para a existência, pois a 
progressão das necessidades sociais demanda cada vez mais a extensão do que seja o mínimo, com o desenvolvimento planejado das políticas públicas que remetam à maximização das condições existenciais.

6. O modelo capitalista impõe ao Estado justificar suas políticas pelos critérios econômicos. O estado atual do capitalismo se revela perverso, porque como meio de incrementar a produção competitiva, gera aumento das desigualdades sociais. Impõe, pela exclusão do trabalho, uma espécie de darwinismo social ao colocar à margem da sociedade capitalista o hipossuficiente, o débil, o enfermo, o imigrante, o pobre que sucumbem na luta com os mais fortes seduzidos pelo lucro a qualquer preço.

7. Os direitos sociais devem ser integralmente promovidos ao fazer prevalecer valores como o da solidariedade e da igualdade substancial perante o individualismo e o capitalismo selvagem. O Estado de Direito não prosperará sem o Estado Social.

8. O modelo de Estado Social mais compatível é aquele que satisfaz as necessidades básicas da população ao concretizar e promover a políticas públicas indispensáveis para assegurar a tutela dos interesses dos seres humanos mais vulneráveis da sociedade.

9. Embora se perceba que os direitos sociais não possam avançar muito na economia capitalista, visto que a oferta de bens materiais e serviços de boa qualidade, bem como a extensão deles para toda a sociedade poderia gerar fortes pressões sobre os cofres públicos; por outro lado, deve ser afastada qualquer resistência que comprometa a sua tutela contra intervenções ilegítimas por parte dos poderes públicos e dos particulares, uma vez que eles ao serem consagrados e reconhecidos nos textos constitucionais não ocupam neste espaço (constitucional) um papel de ornamentação. São preceitos jurídicos de estatura constitucional que devem ser cumpridos como autênticos direitos fundamentais e levados a sério.

10. De todo modo, na interpretação dos direitos fundamentais sociais deve prevalecer o vetor hermenêutico que promove, no mais alto grau possível, a dignidade da pessoa humana e que, na efetivação dos direitos sociais ao estar na dependência de políticas públicas, estas devem ser capazes de aplicar, adequadamente, todos os recursos públicos disponíveis para a maior promoção dos valores essenciais dos seres humanos, contribuindo para o exercício da cidadania, para o aperfeiçoamento da democracia, para a diminuição das desigualdades e para a concretização da justiça social. 


\section{REFERÊNCIAS}

BASTOS, Celso; BRITTO, Carlos Ayres de. Interpretação e aplicabilidade das normas constitucionais. São Paulo: Saraiva, 1982.

BITENCOURT NETO, Eurico. O direito ao mínimo para uma existência digna. Porto Alegre: Livraria do Advogado, 2010.

BRASIL. Decreto $n^{\circ}$ 6.583, de 29 de setembro de 2008. Promulga o Acordo Ortográfico da Língua Portuguesa, assinado em Lisboa, em 16 de dezembro de 1990. Diário Oficial da República Federativa do Brasil, Poder Executivo, Brasília, DF, 30 set. 2008. Seção 1, p.1.

CANOTILHO, José Joaquim Gomes. Direito constitucional e teoria da constituição. 7. ed. Coimbra: Edições Almedina, 2003.

. Jornadas sobre a constituição dirigente em Canotilho.

Curitiba : [s.l.], 2002.

CASTEL, Robert. A insegurança social: o que é ser protegido? Petrópolis: Vozes, 2005.

CAUPERS, João. A agonia do estado social. Revista da Faculdade de Direito da Universidade do Porto, Porto, ano 7, p.45-49, 2010.

CORREIA, José Manuel Sérvulo. Inter-relação entre os regimes constitucionais dos direitos, liberdades e garantias e dos direitos econômicos, sociais e culturais e o sistema constitucional de autonomia do legislador e de separação e interdependência de poderes. Estudos em Homenagem ao Professor Doutor Armando Manuel Marques Guedes. Coimbra, p.969970, 2004.

CUNHA FILHO, Valter Fernandes da. Estado, direito e economia: uma visão realista acerca dos dilemas da efetivação dos direitos sociais nas democracias contemporâneas. In: CLÈVE, Clèmerson Merlin; SARLET, Ingo Wolfgang; PAGLIARINI, Alexandre Coutinho (Coord.). Direitos humanos e democracia. Rio de Janeiro: Forense, 2007. p.463-480. 
DANTAS, Miguel Calmon. Constitucionalismo dirigente e pósmodernidade. São Paulo: Saraiva, 2009.

DÍAZ, Elias. Estado de derecho y sociedad democratica. Bogotá: Taurus, 1998.

FIORAVANTI, Maurizio. Constitución: de la antiguidad a nuestros días. Madrid: Trotta, 2001.

FREITAS, Juarez. A interpretação sistemática do direito. 5. ed. São Paulo: Malheiros, 2010.

GARCÍA-PELAYO, Manuel. Derecho constitucional comparado. Madrid: Alianza, 2000.

HÄBERLE, Peter. Pluralismo y constitución: estudios de teoría constitucional de la sociedad abierta. Madrid: Tecnos, 2002.

HOMEM, António Pedro Barbas. O justo e o injusto. Lisboa: AAFDL, 2001.

LOUREIRO, João Carlos. Adeus ao Estado social? A segurança social entre o crocodilo da economia e a medusa da ideologia dos "direitos adquiridos". Coimbra: Coimbra Editora, 2010.

LOEWENSTEIN, Karl. Political power and the governamental process. 2.ed. Chicago: The University of Chicago, 1965.

LUÑO, Antonio Enrique Pérez. Derechos humanos, estado de derecho y constitución. 9.ed. Madrid: Tecnos, 2005.

MATTEUCCI, Nicola. Organización del poder y libertad: historia del constitucionalismo moderno. Madrid: Trotta, 1998.

MENEZES, Manuel. O "darwinismo social" perante a questão da assistência. Revista Interações, Coimbra, n.15, p.25-40, out. 2008. 
MIRANDA, Jorge. Manual de direito constitucional: direitos fundamentais. 5. ed. Coimbra: Coimbra Editora, 2012. t.4.

MORAIS, José Luís Bolzan de. O Estado e seus limites. Reflexões iniciais sobre a profanação do estado social e a dessacralização da modernidade. In: OLIVEIRA NETO, Francisco José Rodrigues et al. Constituição e estado social: os obstáculos à concretização da constituição. Coimbra: Coimbra Editora, 2008. p.175-195.

NABAIS, José Casalta. Por uma liberdade com responsabilidade: estudos sobre direitos e deveres fundamentais. Coimbra: Coimbra Editora, 2007.

NOVAIS, Jorge Reis. Os princípios constitucionais estruturantes da república portuguesa. Coimbra: Coimbra Editora, 2004.

NUNES, António José Avelãs. As voltas que o mundo dá: reflexões a propósito das aventuras e desventuras do Estado Social. Rio de Janeiro: Lumen Juris, 2011.

NUNES JÚNIOR, Vidal Serrano. A cidadania social na Constituição de 1988: estratégias de positivação e exigibilidade judicial dos direitos sociais. São Paulo: Editora Verbatim, 2009.

OTERO, Paulo. Direitos econômicos e sociais na Constituição de 1976: 35 anos de evolução constitucional. Tribunal Constitucional: $35^{\circ}$ aniversário da Constituição de 1976, Coimbra, v.1, p.37-55, jan. 2012.

. Instituições políticas e constitucionais. Coimbra: Edições Almedina, 2007. v.1.

PORTUGAL. Aviso n ${ }^{\circ} 255$, de 13 de setembro de 2010. Diário da República, Poder Executivo, Lisboa, 17 set. 2010. $1^{\text {a }}$ Série, n. 182, p.4116.

SARLET, Ingo Wolfgang. A eficácia dos direitos fundamentais. 8.ed. Porto Alegre: Livraria do Advogado, 2007. 
VERDÚ, Pablo Lucas. A luta pelo estado de direito. Rio de Janeiro: Renovar, 2007.

ZAGREBELSKY, Gustavo. El derecho dúctil. Madrid: Trotta, 2002.

Recebido em: 2012-12-23

Aprovado para publicação em: 2013-08-13

Como citar: CARVALHO, Osvaldo Ferreira de. A erosão das bases do Estado Social de Direito e o impacto na efetivação dos direitos sociais. Revista do Direito Público, Londrina, v.8, n.2, p.63-90, mai/ago.2013. DOI: 10.5433/1980-511X.2013v8n2p63. 